\title{
Fronteira sul Brasil-Uruguai: A integração cultural em cidades de fronteira
}

\author{
Frontera sur Brasil-Uruguay: La integración cultural en ciudades de \\ frontera
}

South Brazil-Uruguay border: Cultural integration in border cities

\author{
Bel. Bruno César Alves Marcelino ${ }^{1}$
}

\begin{abstract}
Resumo
O presente artigo propõe efetuar uma análise inicial sobre o processo de integração na fronteira sul do Brasil com o Uruguai, tomando como enfoque a integração cultural de base, atribuída à sociedade civil e aos seus processos socioculturais de integração. Como objeto de estudo, delimitou-se a análise do Calendário de Integração Cultural Brasil-Uruguai, criado no âmbito do Comitê de Fronteira.
\end{abstract}

Palavras-Chave: Calendário de integração cultural Brasil-Uruguai; fronteira; integração cultural; sociedade civil.

\section{Resumen}

El presente artículo propone efectuar un análisis inicial sobre el proceso de integración en la frontera sur de Brasil con Uruguay, tomando como enfoque la integración cultural de base, atribuida a la sociedad civil y a sus procesos socioculturales de integración. Como objeto de estudio, se delimitó el análisis del Calendario de Integración Cultural Brasil-Uruguay, creado en el ámbito del Comité de Frontera.

Palabras claves: Calendario de integración cultural Brasil-Uruguay; frontera; Integración cultural; sociedad civil.

\section{Abstract}

The present article proposes to make a initial analysis about the process of integration in the south frontier to the Brazil with the Uruguay, taking as focus the basic cultural integration, who was attributed to the civil society and there sociocultural integration process. As object of study, has delimited the analysis of the calendar of the cultural integration Brazil-Uruguay, created in the scope of the Frontier Committee.

Key words: Calendar of the cultural integration Brazil-Uruguay, Frontier, Cultural Integration, Society.

\section{Introdução}

A faixa de fronteira entre os dois países se estende por um total de 985 quilômetros, desde a tríplice fronteira entre Brasil-Argentina-Uruguai na região oeste até o extremo sul do Brasil na foz do Arroio Chuí no município homônimo, englobando do lado brasileiro o estado do Rio Grande do Sul e do lado uruguaio os departamentos de Artigas,

\footnotetext{
${ }^{1}$ Bacharel em Produção e Política Cultural; mestrando em Integração Contemporânea da América Latina; Centro Latino-Americano de Estudos em Cultura - CLAEC; Foz do Iguaçu, Paraná, Brasil; brunomarcelino@claec.org.
} 
Rivera, Cerro Largo, Treinta y Tres e Rocha. Fazem fronteiras por terra ou via pontes internacionais os municípios de Santana do Livramento (Brasil - BR) e Rivera (Uruguai UY), Quaraí (BR) e Artigas (UY), Jaguarão (BR) e Rio Branco (UY), Barra do Quaraí (BR) e Bella Unión (UY), Chuí (BR) e Chuy (UY) e Aceguá (BR) e Aceguá (UY).

Buscaremos por meio de alguns referenciais teóricos, identificar e discursar criticamente os avanços e/ou retrocessos que ocorreram entre os municípios elencados acima, por meio da implementação do mecanismo utilizado como ferramenta para a promoção da integração cultural da região fronteiriça.

\section{A fronteira e a Integração Cultural}

De acordo com o geógrafo Otto Maull, os principais fins da fronteira são “distinguir o meu do teu; proteger o território nacional; isolá-lo, quando necessário, e facilitar-lhe o intercâmbio, quando conveniente" (apud MATTOS, 2011, p. 112).

Essa definição caracteriza a visão de fronteira presente na concepção institucional e oficial imposto pelo Estado-Nação, que na sua formação, impõe como objetivo principal da fronteira o de proteger seu território e a identidade nacional, impondo uma linha de separação, econômica, social e cultural com os demais Estados. Diferentemente da visão institucional do Estado, presenciamos nas relações de base em regiões de fronteiras, trânsitos culturais e sociais que perpassam os limites interpostos pelo maquinário político-jurídico-administrativo dos Estados.

Bento $(2015$, p.40) nos traz um conceito que trata a fronteira como "espaços físicos, geográficos, de distinção para a afirmação de identidades coletivas situadas nesses territórios específicos". Para ele "fronteiras são invenções culturais, territoriais, de comunidades antigas com territórios e identidades culturais diferentes".

Ele também nos traz uma explanação sobre o fenômeno de integração cultural e social desenvolvido nessas regiões:

Os sujeitos coletivos protagonistas dos processos de construção das experiências de integração regional de Estados são sujeitos localizados no vértice institucional de poder dos Estados e na base popular constitutiva de tais Estados. Porém, enquanto as experiências de integração de vértice podem ser caracterizadas pela transitoriedade dos eventos institucionais, e pela assinatura de acordos para a realização de projetos nem sempre executados, a integração de base é um dado permanente, fático, real, entre as populações das cidades integradas de fronteira (BENTO, 2015, p.46). 

e-ISSN 2016/Atual: 2525-7870 | e-ISSN 2015/2016: 2447-018X

Por meio destes conceitos pretendeu-se analisar a atuação da sociedade civil e das organizações da sociedade civil que foram e/ou são protagonistas como agentes fomentadores da integração cultural e social nas fronteiras onde estão localizadas, considerando as organizações da sociedade civil como organizações e grupos com atuação em torno de projetos de interesse público e sendo os cidadãos locais os protagonistas no desenvolvimento desses. Bento enfatiza que a integração de base, que é advinda dos intercâmbios naturais causados pelo transito de pessoas residentes em ambas as regiões, são as verdadeiras ações concretas de integração cultural e social e não somente as ações propostas pelos governos, que na sua maioria, só reafirma o que já ocorre há anos e até décadas de forma natural pela sociedade civil.

Nesta mesma linha de pensamento Sánchez (2011) afirma que as relações fronteiriças na América Latina, vão além das necessidades apontadas como principais pelos órgãos administrativos do Estado-Nação, para ele as relações são baseadas principalmente nos contextos históricos e culturais dos povos que habitam as fronteiras antes mesmo delas existirem como tais:

Cabe destacar además, que muchas de las comunidades que hoy habitan las fronteras latinoamericanas no se reconocen en las mismas, aunque se pretenda destacar lo contrario desde los centros de poder nacional. Por lo general, las fronteras son habitadas por comunidades asentadas en ellas históricamente y por tanto reconocibles de un extremo y del otro de la línea divisoria, lo que estas no reconocen es la línea que las separa administrativamente pero no afectiva y tradicionalmente. Muchas de estas comunidades regionales para el caso de la América continental son originarias e incluso hablan idiomas diferentes a los oficiales de sus estados nacionales, se identifican a sí mismas como entes individuales y cada vez menos reconocen al estado nación como soporte de salvaguarda de sus identidades (SÁNCHEZ, 2011, p. 3.3.5)

Segundo Mazzei (2012), a fronteira uruguaia com o Brasil representa 6,8\% do total de área de fronteira que o país possuí com os restantes dos países sul-americanos e que abarca um total de 798.478 habitantes residentes nas áreas fronteiriças, sendo que do lado uruguaio o departamento de Cerro Largo é o segundo maior em nível populacional representando $25.7 \%$ da população local. Para Mazzei (2012, p. 35):

Las ciudades fronterizas uruguayo-brasileñas pueden definirse como sociedades cuyos grupos sociales interactúan sostenidos por una convivencia que antepone a restricciones formales su libertad de circulación en la frontera. Serían escenarios en los cuales fluyen solidaridades, asistencias, lealtades, fraternidades, cooperaciones y negociaciones de todo tipo facilitadas por el respaldo directo o indirecto de la sociedad civil organizada a través de distintas representaciones en sus espacios públicos y privados. 
Podemos verificar por meio deste trecho, que essa região foco de nossos estudos, é uma localidade que vive um constante intercâmbio sociocultural, sendo a sociedade civil a principal responsável pela manutenção deste, independente de restrições ou legislações impostas pelos Estados-Nação aqui representados pelos governantes dos dois países. Este intercâmbio contínuo é o responsável pelo sentido da totalidade territorial desta fronteira, gerando a denominada integração fronteiriça de fato e não somente a integração fronteiriça de direito idealizada pelos instrumentos jurídicos e que na prática acaba sendo inviável de se efetivar.

O autor nos fala que essas sociedades têm em prática a "integração de fato" do que a "integração de direito", sendo o seu principal fator o potencial de interação, o imediatismo e a facilidade de intercâmbios, diferentemente do ocorrido com as legislações e acordos legais, "cuyas interacciones, ante la inmediatez y facilidad de intercambios beneficiosos que garantizados por confianzas mutuas generalmente eluden y desafían la cargas de los controles legales" (MAZZEI, 2012, p. 36).

Com base nesses referenciais abordados neste capítulo, iremos agora analisar a sua aplicação no caso específico do Calendário de Integração Cultural Brasil-Uruguai, considerando este como uma ferramenta criada para promover o diálogo e a integração entre a sociedade civil e os seus grupos sociais e culturais dos municípios da região de fronteira entre os dois países.

\section{O Calendário de Integração Cultural como instrumento de integração}

As fronteiras são territórios que possibilitam trocas e intercâmbios culturais entre os diversos grupos sociais e culturais, entendendo também que as fronteiras do ponto de vista dos Estados Nacionais, são demarcações territoriais que servem para definir e defender a soberania e para o controle do seu território.

Na mesma visão da concepção trazida pelo geógrafo Otto Maull, o Estado Nacional passa a reconhecer a modalidade de integração de base nas fronteiras, por ser conveniente ao momento e interessante para fortalecer a integração regional entre países, desta forma ele promove diversas políticas públicas que na realidade já são realizadas no âmbito da base da sociedade que ali vive. Entre essas pode-se elencar a criação das universidades públicas com viés de integração em regiões de fronteiras, como a Universidade Federal do Pampa Unipampa (2008) que abarca municípios fronteiriços da região do pampa gaúcho e a 
Universidade Federal da Fronteira Sul (2009) que abrange municípios da Mesorregião Grande Fronteira Mercosul - Sudoeste do Paraná, Oeste de Santa Catarina e Noroeste do Rio Grande do Sul.

Um outro exemplo da apropriação pelo Estado Nacional de ferramentas de integração de base é a criação no ano de 2014, do Calendário de Integração Cultural Brasil-Uruguai. O projeto teve início junto com a criação do movimento "Fronteras Culturales", no mês de julho de 2010 um grupo de ativistas culturais com o apoio do Ministério da Cultura do Brasil se reuniram na cidade de Santana do Livramento/RS, com representantes de prefeituras e grupos culturais da região da fronteira sul para iniciar uma agenda de atividades que pudessem promover o intercâmbio cultural e a organização de ações conjuntas.

Dentre as ações pensadas pelo movimento a primeira a sair do papel foi a organização da Carta da Fronteira, um documento que traz diversos aspectos socioculturais da fronteira sul, segundo Ricardo Almeida (2015) a carta reconhece a histórica convivência entre ambos os povos da fronteira Brasil-Uruguai que produziu um patrimônio cultural com identidade própria e que a fronteira constitui um corredor cultural no território do Bioma Pampa, com suas singularidades e diversidade ambiental e cultural. $\mathrm{O}$ documento ainda afirma que

[...] a dimensão cultural é um dos eixos integradores para o desenvolvimento sustentável, pois visa a promoção da autoestima e do sentimento de pertencimento, o reconhecimento e valorização do patrimônio histórico e cultural das comunidades fronteiriças e que é importante e urgente fortalecer as ações culturais das comunidades da fronteira, bem como ampliar e democratizar o acesso aos serviços e bens materiais e imateriais, às políticas e ações culturais, e fortalecer a economia da cultura, as capacidades e os saberes locais (RIBEIRO, 2010, p. 01).

Também fruto do movimento e um dos objetivos propostos pela Carta da Fronteira, o Calendário da Integração Cultural Brasil-Uruguai foi discutido e aprovado no dia 16 de abril de 2013 no grupo de trabalho sobre educação e cultura dentro do movimento Fronteras Culturales, tendo posteriormente sua aprovação em uma reunião do Comitê de Fronteira.

O Comitê de Fronteira é um órgão criado com o objetivo de propor políticas públicas de promoção da integração fronteiriça e é composto por representantes do poder público e da sociedade civil organizada de ambos os países, na reunião de aprovação do calendário estavam presentes além dos representantes dos municípios fronteiriços, representantes do Ministério da Educação e Cultura do Uruguai, da Assessoria de Cooperação e Relações Internacionais e da Secretaria de Planejamento, Gestão e Participação Cidadã do Estado do Rio Grande do Sul, membros dos consulados do Brasil e do Uruguai atuantes na região, da 
Unipampa, da UFPel, da Universidade da República do Uruguai e representantes de algumas organizações da sociedade civil dos municípios da região.

Em uma nova reunião do Comitê no dia 27 de setembro de 2013, na cidade de Bagé foram definidos os critérios que seriam utilizados para a escolha dos eventos que comporiam a primeira edição do calendário, bem como a escolha de uma comissão binacional que seria a encarregada pela seleção. Foram definidos quatro critérios que deveriam nortear as escolhas: 1) os eventos devem simbolizar a integração entre os dois países; 2) que promovessem a geração de trabalho e renda na região; 3) que houvesse a participação tanto de brasileiros como de uruguaios em sua organização e 4) que fossem eventos que carregassem o reconhecimento da sociedade da sua região.

No dia 14 de março de 2014, após discussões internas no âmbito do Comitê de Fronteira e dos movimentos sociais que compuseram a comissão binacional de seleção, que foi a responsável por definir quais eventos seriam incluídos na primeira edição, foi lançado o Calendário de Integração Cultural Brasil-Uruguai² 2014, durante o II Encontro de Cidades de Faixa de Fronteira RS, evento organizado pela Frente Nacional de Prefeitos.

Foram selecionados para esta primeira edição os seguintes eventos:

Março - Carnaval Internacional, em Quaraí-Artigas, Livramento-Rivera, Jaguarão-Río Branco e Santa Vitória do Palmar-Chuy.

Abril - Festival Internacional de Pandorgas, em Livramento-Rivera e Semana da Integração Cultural em Santa Vitória do Palmar-Chuy.

Maio - Seminário de Integração Cultural: Protocolo de Intenções Culturais. Brasil Uruguai, em Jaguarão e Río Branco (adiado para os dias 3 e 4 de junho).

Julho - Festival Internacional de Música no Pampa, em Bagé.

Agosto - Festival Binacional de Gastronomia e Mostra Binacional de Teatro em Livramento-Rivera.

\footnotetext{
${ }^{2}$ Maiores informações sobre o Calendário de Integração Cultural Brasil-Uruguai e do Comitê de Fronteira estão disponíveis na página oficial do projeto na rede social Facebook: Em português (Integração Cultural BrasilUruguai) em espanhol (Integración Cultural Uruguay-Brasil).
} 
Setembro - Semana da Integração da Cultura Gaúcha/Gaucha, em Livramento-Rivera e Aceguá-Aceguá.

Outubro - Exposição Feira Agropecuária, em Bagé.

Novembro - Festa Internacional do Churrasco e Festival Internacional de Cinema na Fronteira em Bagé e a Feira Binacional do Livro, em Livramento e Rivera.

Dezembro - Festival Internacional de Balonismo, em Aceguá-Aceguá.

O Calendário sob a responsabilidade do Comitê de Fronteira, é aberto para a inclusão de novos eventos e tanto para a inclusão quanto para a permanência dos atuais, é necessário que os eventos contenham o propósito da integração cultural entre os dois países e cumpram com os quatros critérios descritos anteriormente. Os eventos selecionados, por meio de parceria e auxílios em diferentes modalidades, contam com o apoio da Secretaria de Estado da Cultura do Rio Grande do Sul, do Ministério da Cultura do Brasil, do Ministério da Educação e Cultura do Uruguai, dos Centros MEC do Uruguai, das prefeituras, empresas privadas e organizações da sociedade civil que compõe a região da fronteira sul.

\section{Considerações finais}

Levamos em consideração que apesar da frequente socialização, das grandes relações sociais e do intenso intercâmbio cultural presente nas regiões de fronteiras, estamos falando de uma região que sofre uma grande exclusão dos circuitos culturais, uma região que não tem por parte do Estado, políticas públicas voltadas às suas especificidades e que dialoguem com as recorrentes transformações e transmutações advindas dos seus atributos históricos, geográficos, econômicos, políticos e sociais.

O que se torna evidente em nossos estudos é que, apesar do projeto do Calendário contar com a participação de diversos grupos sociais, observamos que os processos culturais aplicados por estes, leva em conta em sua grande maioria, as influências trazidas pelas variadas culturas presentes na região, percebe-se a presença da cultura afro, da cultura indígena, da cultura europeia, da cultura gaúcha, que se apresentam de forma harmônica traduzidas pelas produções culturais dos grupos, inclusas no calendário de integração cultural.

Considerando as abordagens trazidas por Semprini (1999) sobre multiculturalismo, com base nas observações obtidas com a análise do objeto, pode-se dizer que levando em conta as características específicas da região já elencadas anteriormente, os grupos sociais ali 
presentes por meio da sua produção cultural e social, podem serem caracterizados como espaços multiculturais, pois exalam as diferenças culturais e sociais de seus atores, porém coexistem e defendem as suas especificidades, o que é de difícil alcance para o Estado, ocorre de maneira natural e em grande parte pacifica no dia-a-dia das organizações da sociedade civil e dos grupos socioculturais presentes na região da fronteira sul.

Conforme exposto anteriormente, o papel do Estado Nacional será sempre o de fomentar a unidade entre os povos que compõe a nação, como uma nação de identidade única, sob a argumentação de que para fortalecer o Estado, deve-se ter uma identificação única na sociedade, pois ao se fragmentar a sociedade em grupos étnicos, culturais e sociais acabará ocorrendo rupturas na identidade nacional, provocando desequilíbrios na cultura política liberal adotada pelos Estados Nação.

O que vai na contramão do que ocorre na base da sociedade, a região que se trata a pesquisa, é uma região onde existem pessoas de diversos lugares e com costumes distintos, seja por conta da sua localização fronteiriça, pela grande movimentação sociocultural entre as regiões, onde tradicionalmente ocorrem casamentos e uniões binacionais, com a mescla da cultura uruguaia com a brasileira e por consequência a aculturação de ambas as partes e também pela forte imigração ocorrida durante o século XIX.

Nesse sentido, conforme a análise dos dados, pode-se dizer que as organizações da sociedade civil e os grupos sociais que propuseram os eventos e compuseram os movimentos que culminaram com essa grande movimentação de políticas públicas de integração cultural, são ferramentas vivas de socialização e de integração sociocultural entre os diversos grupos que coexistem nas localidades, pois como demonstrado acima, os projetos e programas executados por essas são resultados deste processo de multiculturalização, eles atuam com grande número de atores sociais, onde cada qual, agrega os seus costumes e tradições.

Esta pesquisa em complementação com uma pesquisa anteriormente executada pelo autor deste trabalho denominada de "Cartografia da Cultura Fronteiriça", demonstram-se como ferramentas de análise da participação da sociedade civil organizada na promoção das políticas de integração cultural e social na região, conforme a explanação do autor:

Compreendendo que a área cultural necessita de uma política pública eficaz e que atenda as especificidades desse campo, e entendendo também que antes de qualquer ação na área cultural se faz necessário um prévio panorama da situação das instituições, coletivos e espaços culturais, o mapeamento realizado pelo projeto Cartografia da Cultura Fronteiriça é uma importante ferramenta de subsídio para a atuação dos governos em suas três instâncias e da sociedade civil articulada. Fez se 
necessário conhecer os grupos, entidades, aparelhos e agentes culturais que atuam nas cenas locais dos municípios de Arroio Grande e Jaguarão, afim de integrar as informações destes espaços através de uma rede atualizada (MARCELINO, 2015, p. 266)

O Calendário de Integração Cultural Brasil-Uruguai demonstra-se sim como uma ferramenta de promoção da integração cultural na fronteira sul do Brasil e norte do Uruguai, pois conforme análise dos dados disponíveis sobre a realização dos eventos, houve o reconhecimento da fronteira em questão como um dos principais centros de integração de base cultural no Mercosul. Contando hoje com o apoio direto de vários organismos públicos de importância nacional como os Ministérios da Cultura de ambos os países, o que de fato agrega valor simbólico sobre a importância das ações desenvolvidas no âmbito do projeto.

Conforme Sánchez (2011) as sociedades oriundas das regiões fronteiriças muitas vezes não reconhecem as linhas divisórias estabelecidas pelos Estados Nações com o intuito de estabelecer um limite de identidade cultural e social de seu território e respectivamente de seu povo, as ações emanadas dos projetos desenvolvidos pelos movimentos sociais da região da fronteira sul vão nesse sentido, utilizam como vetor principal o não reconhecimento da faixa de fronteira, considerando o território como único, dividindo costumes, relações sociais e culturais, festividades, laços familiares entre outros pontos de encontros socioculturais.

A principal crítica a se fazer é, até que ponto a participação massiva do Estado na escolha e fomento dos eventos e dos respectivos grupos sociais que os organizam, torna-se positiva no sentido do protagonismo social da sociedade civil organizada que os promovem, correndo o risco de se perder o principal ponto do projeto que é a integração cultural de base e tornando o numa ferramenta de integração cultural de direito com todas as mazelas e percalços do maquinário político-jurídico-administrativo do Estado Nacional, conforme apontam as contribuições dos autores Mazzei e Bento trazidas anteriormente.

Cabe ressaltar que esta publicação é resultado das discussões e pesquisas elaboradas durante a disciplina "Seminário Teórico: América Latina e as Integrações Regionais" no âmbito do Programa de Pós-graduação em Integração Contemporânea da América Latina ICAL, nível mestrado, da Universidade Federal da Integração Latino-Americana - Unila, recebendo recursos do Edital de Apoio à Participação de Discentes de Pós-graduação Stricto Sensu em Eventos Científicos da Pró-reitoria de Pesquisa e Pós-graduação. 
RELACult - Revista Latino-Americana de Estudos em Cultura e Sociedade

\section{Referências}

ALMEIDA, R. Calendário de Integração Cultural Brasil-Uruguai. In: Fronteiras e relações Brasil-Uruguai. Org: MALLMANN, M. I. e MARQUES, T. C. S. Porto Alegre:

EDIPUCRS, 2015. Disponível em: http://ebooks.pucrs.br/edipucrs/Ebooks/Pdf/978-85-3970691-4.pdf. Acesso em 20 de junho de 2016.

BENTO, F. R. O papel das cidades-gêmeas de fronteira na integração regional SulAmericana. Revista Conjuntura Austral, Vol. 6, n. 27 - 28, p. 40-53, Dez. 2014/Mar. 2015. Disponível em: http://seer.ufrgs.br/index.php/ConjunturaAustral/article/view/51125. Acesso em 20 de junho de 2016.

HERnÁNDEZ SÁNCHEZ, L. E. Concepciones Acerca de la Región en la Problemática Actual de la Integración Latinoamericana. Villa Clara. 2011. Tese de Doutorado - Facultad de Ciencias Sociales - Universidad Central "Marta Abreu" de Las Villas. Disponível em: http://www.eumed.net/tesis-doctorales/2013/lehs/index.htm. Acesso em 22 de junho de 2016.

MARCELINO, B. C. A. Cartografia da Cultura Fronteiriça: A Sociedade Civil e a Promoção das Políticas Culturais. Revista Conexões Culturais, Vol. 01, nº. 02, p. 266, 2015. Disponível em: http://periodicos.claec.org/index.php/cc/article/view/180. Acesso em 20 de junho de 2016.

MATTOS, C. M. Geopolítica - Vol.01. Rio de janeiro: Editora FGV, 2011.

MAZZEI, E. Fronteras que nos unen, límites que nos separan. Montevideo: Imprenta CBA, 2012. Disponível em:

http://www.cci.edu.uy/sites/default/files/Mazzei,\%20E.\%20(2013).\%20Fronteras\%20que\%20 nos\%20unen $\% 20$ y $\% 201 \%$ C3\%ADmites\%20que\%20nos\%20separan. \%20Montevideo\%3A\%2 0Imprenta\%20CBA.pdf. Acesso em 20 de junho de 2016.

SEMPRINI, A. Espaço Público e Espaço Multicultural. In: Multiculturalismo. São Paulo: Edusc, 1999. 